BMJ Open Sport \& Exercise Medicine

\section{Generalised joint hypermobility increases ACL injury risk and is associated with inferior outcome after ACL reconstruction: a systematic review}

To cite: Sundemo D, Hamrin Senorski E, Karlsson L, et al. Generalised joint hypermobility increases ACL injury risk and is associated with inferior outcome after ACL reconstruction: a systematic review. BMJ Open Sport \& Exercise Medicine 2019;5:e000620. doi:10.1136/ bmjsem-2019-000620

- Additional material is published online only. To view please visit the journal online (http://dx.doi.org/10.1136/ bmjsem-2019-000620).

Accepted 29 September 2019

Check for updates

(C) Author(s) (or their employer(s)) 2019. Re-use permitted under CC BY-NC. No commercial re-use. See rights and permissions. Published by BMJ.

For numbered affiliations see end of article.

Correspondence to Dr David Sundemo; david.sundemo@outlook.com

\section{ABSTRACT}

Objectives To investigate the association between generalised joint hypermobility (GJH) and ACL injury risk. Secondary aims involved evaluating associations between GJH and postoperative outcome (including graftfailure risk, knee laxity and patient-reported outcome). Furthermore, we aimed to compare the performance of different grafts in patients with GJH.

Methods Databases MEDLINE/PubMed, EMBASE and the Cochrane Library were searched, including 2760 studies. Two reviewers independently screened studies for eligibility. A modified version of the MINORS score was applied for quality appraisal. Studies assessing GJH while reporting the risk of ACL injury and/or postoperative outcome were included.

Results Twenty studies were included, using several different methods to determine GJH. There was consistent evidence showing that GJH is a risk factor for unilateral ACL injury in males, while in females, the results were conflicting. There was limited evidence associating GJH with increased knee laxity 5 years postoperatively. There was consistent evidence of inferior postoperative patient-reported outcome in patients with GJH. Moreover, there was limited yet consistent evidence indicating that patellar-tendon autografts are superior to hamstringtendon autografts in patients with GJH in terms of knee laxity and patient-reported outcome. There was insufficient evidence to draw conclusions regarding the outcomes of bilateral ACL injury and graft failure.

Conclusions In men, GJH was associated with an increased risk of unilateral ACL injury. Moreover, GJH was associated with greater postoperative knee laxity and inferior patient-reported outcome. Based on the available evidence, a patellar-tendon autograft appears to be superior to a hamstring-tendon autograft in patients with GJH. However, the included studies were heterogeneous and there is a need for consensus in the assessment of GJH within sports medicine.

\section{INTRODUCTION}

The investigation of risk factors for ACL injury has been a subject of interest during the last few decades. Injuries to the ACL are

\section{What is already known?}

Generalised joint hypermobility is associated with knee injuries in general.

- Generalised joint hypermobility is associated with articular pain and reduced quality of life in the general population.

- There have been conflicting reports associating the existence of generalised joint hypermobility with ACL injury, graft failure and postoperative outcome.

\section{What are the new findings?}

Compared with normal joint mobility, men with generalised joint hypermobility have a greater risk of rupture of the ACL.

- Generalised joint hypermobility is associated with inferior patient-reported outcome after ACL reconstruction.

- Limited evidence indicates that patellar-tendon autografts are superior to hamstring-tendon autografts, in patients with generalised joint hypermobility, in terms of patient-reported outcome and postoperative knee laxity.

caused by intricate interplay between intrinsic and extrinsic risk factors in combination with injury mechanisms. ${ }^{12}$ One potential risk factor for ACL injury, which is attracting increasing interest, is generalised joint hypermobility (GJH). GJH has been shown to increase the risk of sustaining knee injuries in general, ${ }^{3}$ and it has also been associated with ACL injury risk, ${ }^{4}$ the risk of contralateral ACL injury $^{5}$ and inferior postoperative outcomes. ${ }^{6}$ However, a recent study reported no association between GJH and ACL injury risk. ${ }^{7}$ As a result, there is a need to evaluate the scientific evidence in this regard.

$\mathrm{GJH}$ is defined merely as hyperextensibility of the synovial joints with the ability to extend, passively and/or actively, beyond 
the normal physiological range of motion. GJH may be present in isolation, in combination with symptoms (eg, pain, fatigue or joint dislocations) or as a feature in a clearly defined syndrome, such as hereditary connectivetissue disorders. Previously, the term GJH has been used by several researchers within different subspecialised areas, although the definitions have differed between researchers. In 2017, a consensus statement and a clarification of hypermobility terminology were published in order to clearly define GJH and thus facilitate the more stringent use of this term forthwith. ${ }^{89}$ In short, the statement suggests standardised testing procedures, and that individualised cut-off values should be used to define GJH, depending on the age, sex and maturity of the individuals. In specific conditions, a standardised questionnaire can be used. ${ }^{10}$ The prevalence of GJH ranges from $2 \%$ to $57 \%$, depending on the definition and methods used. ${ }^{11-14}$ A large, recent study of a general Danish population found that the self-reported prevalence of GJH and knee joint hypermobility was $13 \%$ and $23 \%$, respectively. ${ }^{15} \mathrm{GJH}$ is more common in young persons and in females and the prevalence varies with ethnic background. ${ }^{11}$ Interestingly, sex and age have also been mentioned as individual risk factors for ACL injury. ${ }^{16-18}$

Previous systematic reviews have assessed risk factors for ACL injury, where GJH has been included. ${ }^{2} 31920$ However, the previous systematic review including most articles specifically assessing GJH in relation to ACL injury only included two studies in this respect. ${ }^{231920}$ Moreover, no review has evaluated the postoperative effects of GJH in patients with an ACL injury.

The primary purpose of this study was to investigate the influence of GJH on ACL injury risk. The secondary purpose was to investigate the influence of GJH on postoperative outcome (including graft-failure risk, knee laxity, patient-reported outcome) and to compare the performance of different graft types in patients with GJH.

\section{METHODS}

This systematic review was performed in accordance with the Preferred Reporting Items for Systematic Reviews and Meta-Analyses guidelines. ${ }^{21}$

\section{Study eligibility}

All original clinical studies, including prospective and retrospective studies, written in English and assessing GJH in relation to ACL injury, were considered for inclusion. Different methods are used to define GJH and, for this reason, all publications assessing $\mathrm{GJH}$ and relating to the primary or secondary purposes were included. The definition of GJH used by the authors of each individual study was also used to define hypermobility in this systematic review, but the authors had to report the summarised total score of GJH in order to be included. Postoperative clinical outcomes after ACL reconstruction (including graft-failure risk, knee laxity and patientreported outcome) were not specified in detail in order to review all the possible data available. Studies reporting knee laxity or knee hypermobility alone were excluded. Review articles, expert opinions, cadaver studies, animal studies and case reports were excluded.

\section{Literature search}

An expert medical librarian performed the literature search at the Biomedical Library in Gothenburg, Sweden, on 6 February 2018. An updated literature search was conducted on 11 January 2019 using a previously described method. ${ }^{22}$ The MEDLINE/PubMed, EMBASE and the Cochrane Library databases were searched. Two general concepts were used to systematise the search. The first concept related to the ACL and ACL injury and the other concept pertained to hypermobility, accessible in the supplementary material (online supplementary table 1). The search was deliberately broad in an effort to include all relevant articles.

\section{Study selection and data abstraction}

Two authors (DS, LK) independently reviewed all the titles, abstracts and full-text articles. Data were abstracted by the medical librarian, in co-operation with the first author, and placed in an EndNote library (Clarivate Analytics, Philadelphia, USA). The publications were then extracted into the Rayyan web application for systematic reviews to facilitate the review process. ${ }^{23}$ Publications were then read in full text for the assessment of eligibility. Consensus discussions were held in the event of disagreement.

\section{Quality assessment}

A critical appraisal of study quality was made using the Methodological Index for Non-Randomized Studies (MINORS). ${ }^{24}$ Two authors (DS, AH) independently graded the quality of the included studies. Consensus discussions were held in the event of disagreement. Eight items relating to non-comparative studies and an additional 4, making 12 in total, were used for comparative studies. The MINORS assessment was originally used to assess longitudinal observational studies. However, the present systematic review includes several case-control studies, making items 6 and 7 irrelevant, and these items were therefore excluded for studies with a case-control study design. All items are graded on a scale ranging from 0 to 2. This gives a potential total of 16, 20 and 24 for non-comparative, case-control and comparative studies, respectively. For the interpretation of the results of non-comparative studies, the scores can be understood as follows: $0-4$, very low quality; $5-8$, low quality; $9-12$, fair quality; and $13-16$, high quality. ${ }^{25}$ For comparative studies, the scores can be interpreted as $0-6$, very low quality; 7-12, low quality; $13-18$ fair quality and 19-24, high quality. ${ }^{25}$ There is no consensus on predefined cutoffs for case-control studies using the MINORS score. The exact conditions for the distribution of the MINORS scores are specified in the online supplementary material. 
Table 1 Articles included in the final review

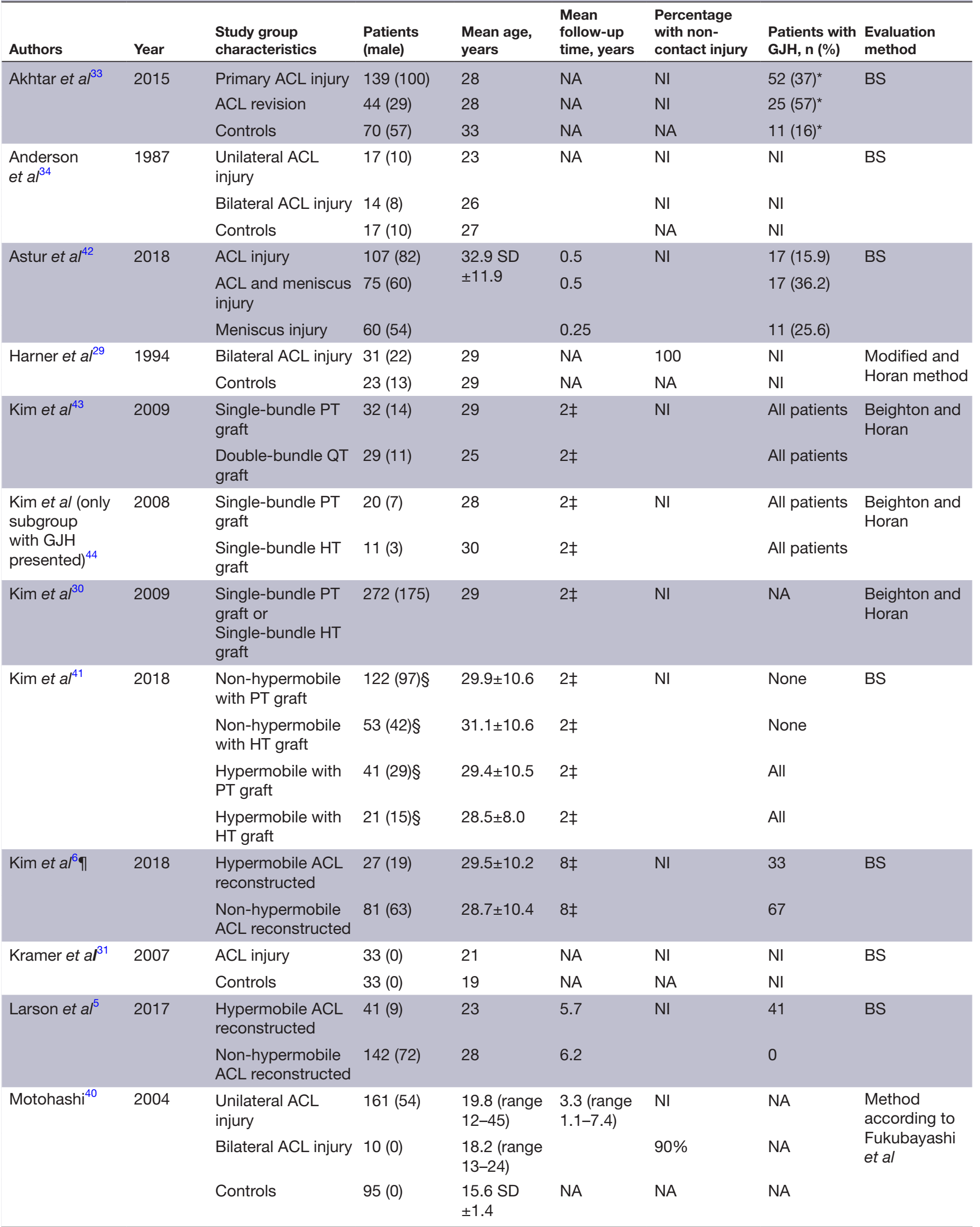


Table 1 Continued

\begin{tabular}{|c|c|c|c|c|c|c|c|c|}
\hline Authors & Year & $\begin{array}{l}\text { Study group } \\
\text { characteristics }\end{array}$ & $\begin{array}{l}\text { Patients } \\
\text { (male) }\end{array}$ & $\begin{array}{l}\text { Mean age, } \\
\text { years }\end{array}$ & $\begin{array}{l}\text { Mean } \\
\text { follow-up } \\
\text { time, years }\end{array}$ & $\begin{array}{l}\text { Percentage } \\
\text { with non- } \\
\text { contact injury }\end{array}$ & $\begin{array}{l}\text { Patients with } \\
\text { GJH, n (\%) }\end{array}$ & $\begin{array}{l}\text { Evaluation } \\
\text { method }\end{array}$ \\
\hline \multirow[t]{2}{*}{$\begin{array}{l}\text { Ramesh } \\
\text { et } a l^{35}\end{array}$} & \multirow[t]{2}{*}{2005} & ACL injury & $169(137)$ & $\begin{array}{l}\text { Range } \\
18-34\end{array}$ & NA & $75.4 \%$ & $72(42.6)$ & \multirow[t]{2}{*}{ BS } \\
\hline & & Controls & $65(\mathrm{NI})$ & $\begin{array}{l}\mathrm{NI} \text {, age } \\
\text { and gender } \\
\text { matched }\end{array}$ & NA & NA & $14(21.5)$ & \\
\hline $\begin{array}{l}\text { Scerpella } \\
\text { et } a l^{38}\end{array}$ & 2005 & Controls & $181(89)$ & $\begin{array}{l}\text { Males: } 20.1 \\
\text { SD } \pm 1.4 \\
\text { Females: } \\
19.5 \text { SD } \\
\pm 1.2\end{array}$ & NA & NA & NA & $\begin{array}{l}\text { BS and a } \\
\text { modified } \\
\text { version }\end{array}$ \\
\hline \multirow[t]{2}{*}{ Shimozaki et al ${ }^{7}$} & \multirow[t]{2}{*}{2018} & ACL injury & $12(0)$ & $\begin{array}{l}15.4 \text { SD } \\
\pm 0.3\end{array}$ & 3 & 12 & $N A^{\star \star}$ & \multirow[t]{2}{*}{ BS } \\
\hline & & Controls & $156(0)$ & $\begin{array}{l}15.5 \text { SD } \\
\pm 0.3\end{array}$ & 3 & NA & $N A^{\star *}$ & \\
\hline \multirow[t]{2}{*}{ Stijak et $a l^{37}$} & \multirow[t]{2}{*}{2014} & ACL injury & $29(29)$ & 26.6 & NA & 100 & $\mathrm{NI}$ & \multirow[t]{2}{*}{ BS } \\
\hline & & Controls & $29(29)$ & 27.1 & NA & NA & $\mathrm{NI}$ & \\
\hline \multirow[t]{2}{*}{ Stijak et $a l^{39}$} & \multirow[t]{2}{*}{2014} & ACL injury & $12(0)$ & 24.2 & NA & 100 & $\mathrm{NI}$ & \multirow[t]{2}{*}{ BS } \\
\hline & & Controls & $12(0)$ & 24.8 & NA & NA & $\mathrm{NI}$ & \\
\hline \multirow{2}{*}{$\begin{array}{l}\text { Uhorchak } \\
\text { et al }\end{array}$} & \multirow[t]{2}{*}{2003} & ACL injury & $24(16)$ & 18.4 (range & 4 (both & 100 & NA & \multirow[t]{2}{*}{ BS } \\
\hline & & Uninjured controls & $835(723)$ & 17-23) & groups) & NA & NA & \\
\hline
\end{tabular}

*Using the $>4$ cut-off limit.

tWith modifications.

$\ddagger$ The exact follow-up time was not disclosed.

$\S$ The presented patients were followed up for 2 years, fewer patients were examined at the 5-year follow-up.

ПOnly the patients in the 8-year follow-up were included, as the same patients from the 2-year and 5-year follow-ups appear to be presented in the following article by Kim et al.

${ }^{\star *}$ Patients not dichotomised into hypermobile/non-hypermobile.

BS, Beighton Score; GJH, generalised joint hypermobility; HT, hamstring tendon; NA, not applicable; NI, no information; PT, patellar tendon; QT, quadriceps tendon.

\section{Data synthesis}

Data synthesis was performed by presenting tables and summarising the results using a qualitative approach. Quantitative summarisation, using a meta-analysis, was considered, but it was ultimately not implemented owing to the heterogeneity of the data found in the included studies. The results section begins by summarising the methods used to assess GJH in the included studies. The results include the following sections: Risk of ACL injury (main heading), Unilateral ACL injury and Bilateral ACL injury. The postoperative results were presented as follows: Postoperative outcomes (main heading), Graft failure, Knee laxity, Patient-reported outcome, Osteoarthritis and Graft choice in patients with GJH.

\section{RESULTS}

The initial search generated 2760 articles that were screened by title and abstract and 59 of them were read in full text. Three studies analysed the influence of GJH on knee injuries in general, without any specific analysis of ACL injury risk, and they were therefore excluded from further analysis. ${ }^{26-28}$ Finally, 20 articles contained relevant information and were included in the qualitative synthesis (table 1 and online supplementary figure $1)$. 


\section{Appraisal of evidence}

The mean (range) MINORS score were 9 (9-9), 13 (7-18) and 17 (13-19) for non-comparative studies, casecontrol studies and comparative studies, respectively. The quality of the non-comparative studies was interpreted as fair. For comparative studies, the quality ranged between fair and high, with a majority of studies of fair quality.

The principal methodological strengths overall include the reporting of a clearly stated aim (item 1), the inclusion of consecutive patients (item 2), the use of appropriate endpoints (item 4), a follow-up of more than 2 years (item 6 ) and the use of adequate and contemporary control groups (items 9 and 10).

The main methodological weaknesses involved the uneven reporting of the timing of data collection; if prospectively or retrospectively collected (item 3). Demographic baseline equivalence (item 11) was unevenly reported (table 2). Although not involved as a specific item in the MINORS score, the use of multivariable analysis in the assessment of ACL injury risk factors is important. Only six studies used multivariable, or partly multivariable analyses, considering the influence of potential confounders on the investigated outcome. ${ }^{4729-32}$ Furthermore, only eight studies used prospective power analysis (table 2) and one study appears to have performed a post hoc power analysis. ${ }^{32}$

\section{Classification of GJH}

Six principal methods were used to determine GJH, although minor differences existed within these groups. The scale of hypermobility scores ranged from 4 to 9 points among the methods, a difference partly due to whether tests were performed unilaterally or bilaterally. There was considerable variation in terms of how the authors of the included studies reported the method of executing the hypermobility tests. Methods that were deemed, by the authors of this review, as not easily reproducible can be found in online supplementary table 2. The most frequently implemented method was the Beighton Score (BS), using the 9-point scale, which was used in 12 studies. In these 12 studies, 4 different cut-offs were used to determine the presence of hypermobility and four studies did not use a cut-off at all (online supplementary table 2).

\section{GJH as a risk factor for ACL injury}

\section{Unilateral ACL injury}

Eleven studies investigated the effect of GJH on the risk of primary ACL injury. Five of the studies presented the results for groups including individuals of both sexes, ${ }^{43-36}$ all showing significant associations between GJH and ACL injury. Three of the studies with both sexes were either statistically adjusted for age and sex or the control subjects were matched to the cases during enrolment to the study. ${ }^{33} 34{ }^{36}$ One of the studies also analysed the relative risk of ACL injury in individuals with GJH, showing a relative risk of 2.8, 3.1 and 2.7, respectively, for all individuals, males only and females only. ${ }^{4}$ In one of the five studies, including participants from both sexes, calculated the OR for the presence of hypermobility in patients with an ACL injury (OR 4.46, 95\% CI 2.58 to 7.71). ${ }^{36}$

In four studies, males were analysed separately. In three of these studies, significant associations were found between ACL injury and GJH; all the studies were controlled for the age of the participants. ${ }^{42} 37$ In the fourth study assessing males specifically, by Scerpella $e t a l$, two methods of evaluating GJH were used; one showed a significant association, while the other did not (details of the methods available in online supplementary table 2). However, in this study, there were age differences between the groups where the injured individuals were significantly older (table 3$).^{38}$

Females were analysed separately in six studies. Two studies showed significant associations between GJH and ACL injury, one of which was controlled for age, ${ }^{4}$ but in the other study it was unclear if the age of the participants was considered. ${ }^{31}$ Two studies did not find a significant association ${ }^{32} 39$ and another study found that a lower level of BS points was associated with an increased the risk of ACL injury. ${ }^{7}$ However, when logistic regression analysis was used, GJH had no effect on ACL injury risk. ${ }^{7}$ Finally, Scerpella $e t a \vec{l}^{8}$ found that, using BS, there was no association with ACL injury. However, using the modified hypermobility score, with less strict limits for the degree of hyperextension, a significant association was observed (table 3).

Taken together, there was consistent evidence of association between GJH and the risk of unilateral ACL injury in males, while in females the results were conflicting.

\section{Bilateral ACL injury}

The occurrence of bilateral ACL injury was assessed in five studies. One study found that patients with bilateral ACL injuries had higher hypermobility scores when compared with patients with unilateral ACL injuries. This study consisted of only females, but the analysis was not adjusted for the difference in age. ${ }^{40}$ The other four studies found no significant association between the incidence of bilateral/contralateral ACL injury and GJH (online supplementary table 3). ${ }^{563441}$

Taken together, there was insufficient evidence to draw any conclusions regarding the influence of GJH on bilateral ACL injury risk.

\section{Postoperative outcomes \\ Graft failure}

In the current review, graft failure includes both failure due to rupture and due to a lax dysfunctional graft, owing to the underlying study material. Two studies reported only graft ruptures. ${ }^{61}$ Two other studies used the definition graft failure, including failure both due to graft ruptures and due to increased graft laxity. ${ }^{53}$ Thus, a total of four studies observed the occurrence of graft failure. 
Two studies, using a quadruple hamstring-tendon (HT) autograft, a patellar-tendon (PT) autograft, a fascia-lata autograft or an allograft found significant associations with hypermobility. ${ }^{53}$ In the other two studies, the graft failure rate was consistently higher in the group with $\mathrm{GJH}$, irrespective of graft type, though the results were not statistically significant. These two studies confirmed baseline equivalence in terms of sex and age, whereas the studies with a significant association did not (online supplementary table 4 ).

Taken together, there was insufficient evidence to draw conclusions in terms of the influence of GJH on graft failure risk.

\section{Knee laxity}

The Lachman test and the pivot-shift test were evaluated in two studies. At the 5-year ${ }^{41}$ and 8-year ${ }^{6}$ follow-ups, significantly increased anteroposterior laxity was observed in patients with $\mathrm{GJH}$, using the Lachman test, irrespective of whether PT or HT grafts were used (table 4). Increased rotatory knee laxity, measured with the pivot-shift test, was observed in patients with PT grafts at the 5-year and 8-year follow-ups in patients with $\mathrm{GJH}^{641}$ but not in patients with HT autografts. ${ }^{41}$ The same surgical technique was used in both studies, with transtibial drilling of the femoral socket.

Anterior tibial translation was assessed in three studies. The mean side-to-side difference using the KT-2000 was significantly larger in patients with $\mathrm{GJH}$ at both the 5-year and 8-year follow-ups in two studies. ${ }^{641}$ One study, using the KT-1000, found no significant difference in anterior tibial translation between groups at a mean of approximately 6 years postoperatively. ${ }^{5}$

Taken together, there was limited evidence associating GJH with increased anteroposterior knee laxity 5 and 8 years postoperatively. There was conflicting evidence in terms of the magnitude of rotatory knee laxity at 5 years and very limited evidence indicating increased rotatory knee laxity at 8 years postoperatively.

\section{Patient-reported outcome}

The Lysholm and International Knee Documentation Committee (IKDC) scores were evaluated in four comparative studies, showing inferior outcomes in patients with GJH after $2,{ }^{30} 415,{ }^{41} 6^{5}$ and $8^{6}$ years postoperatively. Inferior outcomes for patients with GJH were also reported using the Cincinnati knee rating system 6 years postoperatively. ${ }^{5}$ The level of physical activity, using the Tegner Activity Scale, was assessed in one non-comparative study of patients with GJH. The follow-up time was only 6 months and no correlation between hypermobility and the level of activity was found (table 5). ${ }^{42}$

Taken together, there was limited but consistent evidence of inferior patient-reported outcome in patients with $\mathrm{GJH}$ and previous ACL reconstruction. 
Table 3 Risk of unilateral ACL injury

\begin{tabular}{|c|c|c|c|c|c|c|c|c|}
\hline \multirow[b]{2}{*}{ Author } & \multirow{2}{*}{$\begin{array}{l}\text { Patients, } \mathbf{n} \\
\text { injury/control } \\
\text { (male) }\end{array}$} & \multicolumn{2}{|c|}{$\begin{array}{l}\text { Mean hypermobility } \\
\text { score * }\end{array}$} & \multicolumn{2}{|c|}{$\begin{array}{l}\text { Proportion of } \\
\text { hypermobile patients (\%) }\end{array}$} & \multirow{2}{*}{$\begin{array}{l}\text { Risk of ACL injury, } \\
\text { OR }(95 \% \mathrm{Cl}) \\
\text { Hypermobile }\end{array}$} & \multirow[b]{2}{*}{$P$ value } & \multirow{2}{*}{$\begin{array}{l}\text { Consideration for } \\
\text { differences in sex } \\
\text { and age }\end{array}$} \\
\hline & & $A C L$ injury & Controls & ACL injury & Controls & & & \\
\hline Akhtar et $\left.a\right|^{33}$ & 209 (157) & 2.9 & 1.4 & & & & 0.002 & $\mathrm{~S}$ and $\mathrm{A}$ matcheo \\
\hline Anderson et a $\left.\right|^{34}$ & $34(20)$ & 2.8 & 1.2 & & & & 0.033 & $\mathrm{~S}$ and $\mathrm{A}$ matched \\
\hline Kramer et al ${ }^{31}$ & $66(0)$ & 5.2 & 3.8 & & & & 0.01 & Similar age \\
\hline Ramesh et $\left.a\right|^{35}$ & $234(\mathrm{NI})$ & & & 42.6 & 21.5 & & $<0.05$ & No \\
\hline \multicolumn{9}{|l|}{ Scerpella et $a{ }^{38}$} \\
\hline BS, males & $103(103)$ & $1.6 \pm 1.6$ & $1.1 \pm 1.4$ & & & & NS & A difference $\neq$ \\
\hline BS, females & $114(0)$ & $2.5 \pm 2.1$ & $2.5 \pm 1.7$ & & & & NS & A difference \\
\hline AHS, males & $103(103)$ & $4.2 \pm 2.1$ & $2.5 \pm 2.1$ & & & & $<0.05$ & A difference $\ddagger$ \\
\hline AHS, females & $114(0)$ & $5.4 \pm 2.6$ & $4.3 \pm 2.2$ & & & & $<0.05$ & A difference $\neq$ \\
\hline Shimozaki et al ${ }^{\top}$ & $168(0)$ & $1.8 \pm 1.3$ & $2.7 \pm 2.2$ & & & & 0.04 & A matched \\
\hline Stijak et $a l^{37}$ & $29(29)$ & $4 \S$ & $2.3 \S$ & & & & 0.005 & A matched \\
\hline Stijak et $a l^{39}$ & $12(0)$ & $4.7 \S$ & $5 \S$ & & & & NS & A matched \\
\hline \multicolumn{9}{|l|}{ Uhorchak et al ${ }^{4}$} \\
\hline All patients & 859 (739) & $3.5 \pm 2.7$ & $1.8 \pm 2.1$ & & & & $<0.001$ & A matched \\
\hline Males & 739 (739) & $2.9 \pm 2.7$ & $1.6 \pm 2.0$ & & & & 0.003 & \\
\hline Females & $120(0)$ & $4.6 \pm 2.5$ & $3.2 \pm 2.4$ & & & & 0.014 & \\
\hline Vacek et $\left.\mathrm{a}\right|^{32}$ & $336 \rrbracket$ & & & & & & & \\
\hline Males & & & & & & 1.3 (1.1 to 1.7$)$ & 0.025 & A matched \\
\hline Females & & & & & & $\mathrm{NI}$ & NS & A matched \\
\hline Vaishya and Hasija ${ }^{36}$ & $300(190)$ & & & 60.5 & 25.5 & & $<0.01$ & $\mathrm{~S}$ and $\mathrm{A}$ matched \\
\hline
\end{tabular}

*The particular method for each study of evaluation of hypermobility can be seen in the online supplementary table 2 .

tUnclear if there was a statistical difference in age between the groups.

$\ddagger$ Statistical significant difference in age between the groups.

\$Measured graphically using ImageJ from Figure 4 in the respective articles.

INo information regarding the sex of the controls.

A, age; AHS, Adjusted Hypermobility Score; BS, Beighton Score; NI, no information; NS, not significant; S, sex.

\section{Osteoarthritis}

The development of osteoarthritis (OA) was evaluated, using radiography, in two comparative studies. No significant differences in terms of the incidence of OA between patients with and without GJH were found after 2, 5 or 8 years (online supplementary table 5 ) ${ }^{641}$

Taken together, there was limited evidence showing no effect of GJH on the development of OA in the short to mid-term follow-up. No evidence exists evaluating the influence of GJH in the long-term perspective.

\section{Graft choice in patients with GJH}

Four studies evaluated the effect of graft choice in ACLreconstructed patients with $\mathrm{GJH}$, all from the same research group.

Knee laxity was assessed using four different methods. Using the Lachman test, a double-bundle (DB) quadriceps-tendon (QT) autograft produced less knee laxity compared with a PT autograft in one study (table 6) ${ }^{43}$ The difference between PT and HT autografts was evaluated in two studies, showing less knee laxity for the PT in one study ${ }^{44}$ at 2 years postoperatively, but, at 5 years postoperatively, there was no difference between the grafts. ${ }^{41}$ Evaluating the pivot-shift test, one study reported less rotatory knee laxity using PT autografts compared with HT autografts at 2 years postoperatively. ${ }^{44}$ Using the KT-2000, one study reported less intrumented anteroposterior knee laxity using DB-QT autografts compared with PT autografts. ${ }^{43}$ Consistently less instrumented anteroposterior knee laxity was reported using the PT autograft in studies compared with the HT autograft, ${ }^{43} 44$ although, in one of the studies, no statistical analysis was performed (table 6$).{ }^{30}$

There was no difference in the Lysholm score between DB-QT autografts and PT autografts. ${ }^{43}$ However, higher Lysholm scores were reported for patients receiving the PT autograft, at 2 and 5 years, compared with patients receiving the HT autograft. ${ }^{414}$ The two studies assessing the Hospital for Special Surgery and the IKDC (classified as $\mathrm{A}, \mathrm{B}, \mathrm{C}$ and $\mathrm{D}$ ) scores were unable to find any differences with regard to graft type. ${ }^{43} 44$ The IKDC score was, however, higher in patients receiving the PT autograft compared with patients with the HT autograft in one study, both 2 and 5 years postoperatively (table 6 ). ${ }^{41}$

There was limited, yet consistent evidence that PT autografts were superior to HT autografts in patients with $\mathrm{GJH}$, with PT autografts showing a reduced risk of 
Table 4 Postoperative knee laxity in relation to the presence of GJH

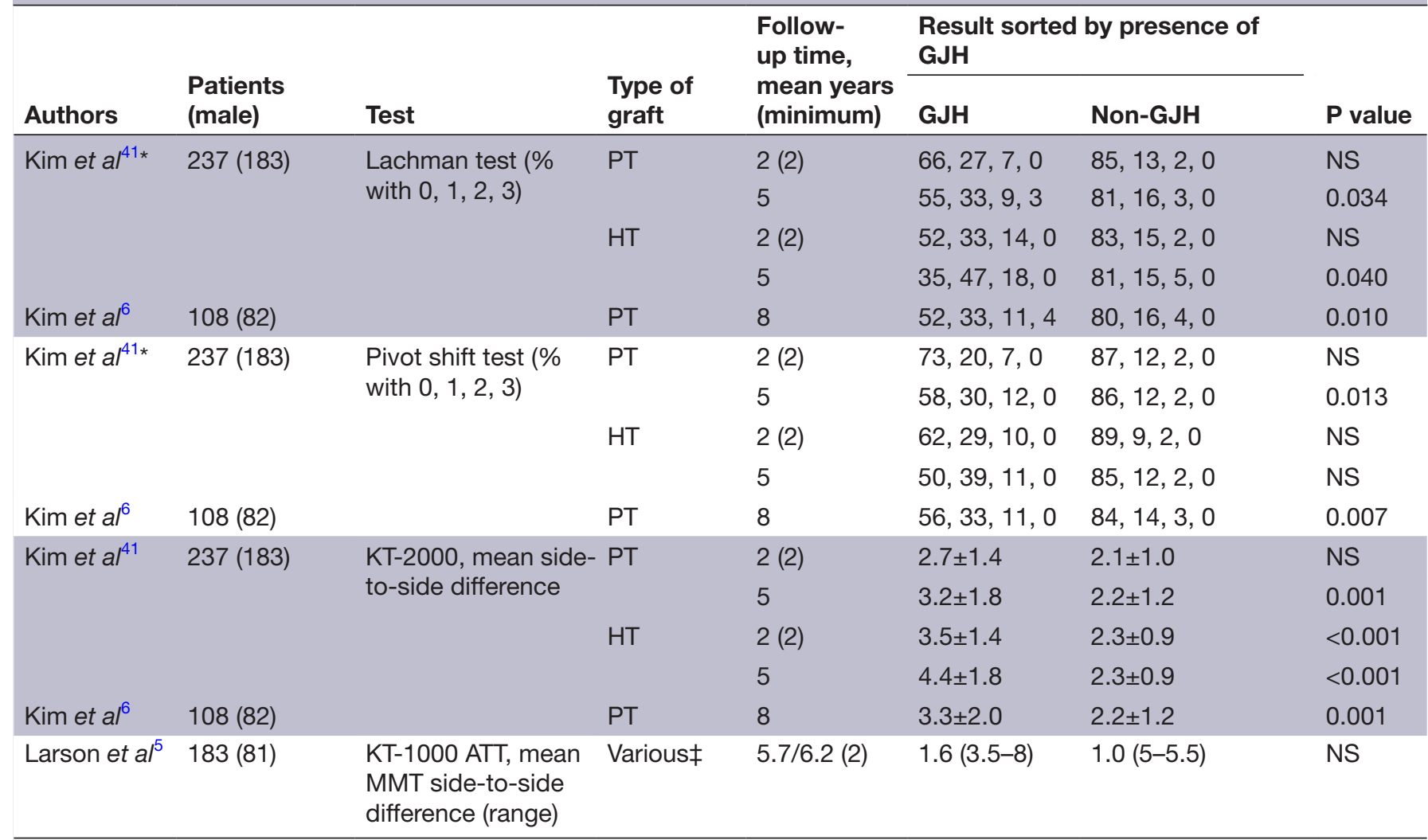

${ }^{*}$ The $p$ values of the Bonferroni correction analysis are presented for this publication.

†The exact follow-up time was not disclosed.

‡PT autograft (46), PT allograft (43), quadrupled HT autograft (85), tibialis anterior allograft (9).

ATT, anterior tibial translation; GJH, generalised joint hypermobility; HT, hamstring tendon; MMT, manual maximum test side-to-side difference with a force of $134 \mathrm{~N}$; NS, not significant; PT, patellar tendon.

increased anteroposterior laxity and improved patientreported outcome. Very limited evidence suggests that DB-QT autografts produce less knee laxity, but with no difference in patient-reported outcome, in comparison with PT autografts.

\section{DISCUSSION}

The most important finding in this review was that there is an increased risk of ACL injury in individuals with GJH. This is similar to a previous meta-analysis assessing the influence of GJH on knee injuries in general, ${ }^{3}$ although, since the publication of that particular meta-analysis, additional studies have reported conflicting results. ${ }^{26} 45$ The increased risk of primary ACL injury in individuals with GJH found in this review could not be established when analysing female individuals separately. In females, the results were more ambiguous. This is surprising, since female $\operatorname{sex}^{1646}$ and GJH are regarded as important risk factors for ACL injury and hypermobility is more common in females. ${ }^{11}$ Because of this, we hypothesised that part of the reason for the increased risk of ACL injury, seen in females, could be attributed to hypermobility. However, in females, other possible risk factors, such as reduced neuromuscular control, ${ }^{47-50}$ a narrow femoral notch ${ }^{451}$ or hormonal factors, could be of greater significance. ${ }^{52}$

\section{Postoperative outcomes}

The results showing increased postoperative laxity, with no difference at 2 years but an increase in the group with $\mathrm{GJH}$ at 5 and 8 years, are interesting. It appears that the $\mathrm{GJH}$ has a greater impact on postoperative knee laxity after 2 years have passed, beyond the immediate rehabilitation phase. Possibly, repetitive strain on the ACL graft has a different effect on the collagen tissue in the graft in patients with GJH. GJH is related to alterations and impairment of the extracellular matrix, primarily collagen, elastin and fibrillin. ${ }^{53}$ Interestingly, one study has demonstrated that biological failures were associated with GJH. ${ }^{33}$ Biological failures were, by the authors, defined as faliures where no technical cause could be identified and where no traumatic injury had occurred. In $74 \%$ of the cases in the group with biological failures, the patients' grafts were intact but lax (non-functional according to the authors). Thus, increasing joint hypermobility may be associated with increased risk of biological failure, as defined above, with the difference becoming more obvious after the first 2 years after ACL reconstruction.

There was considerable agreement between studies showing that $\mathrm{GJH}$ has a negative influence on postoperative patient-reported outcome in patients with previous 
Table 5 Postoperative patient-reported outcome in relation to presence of generalised joint hypermobility

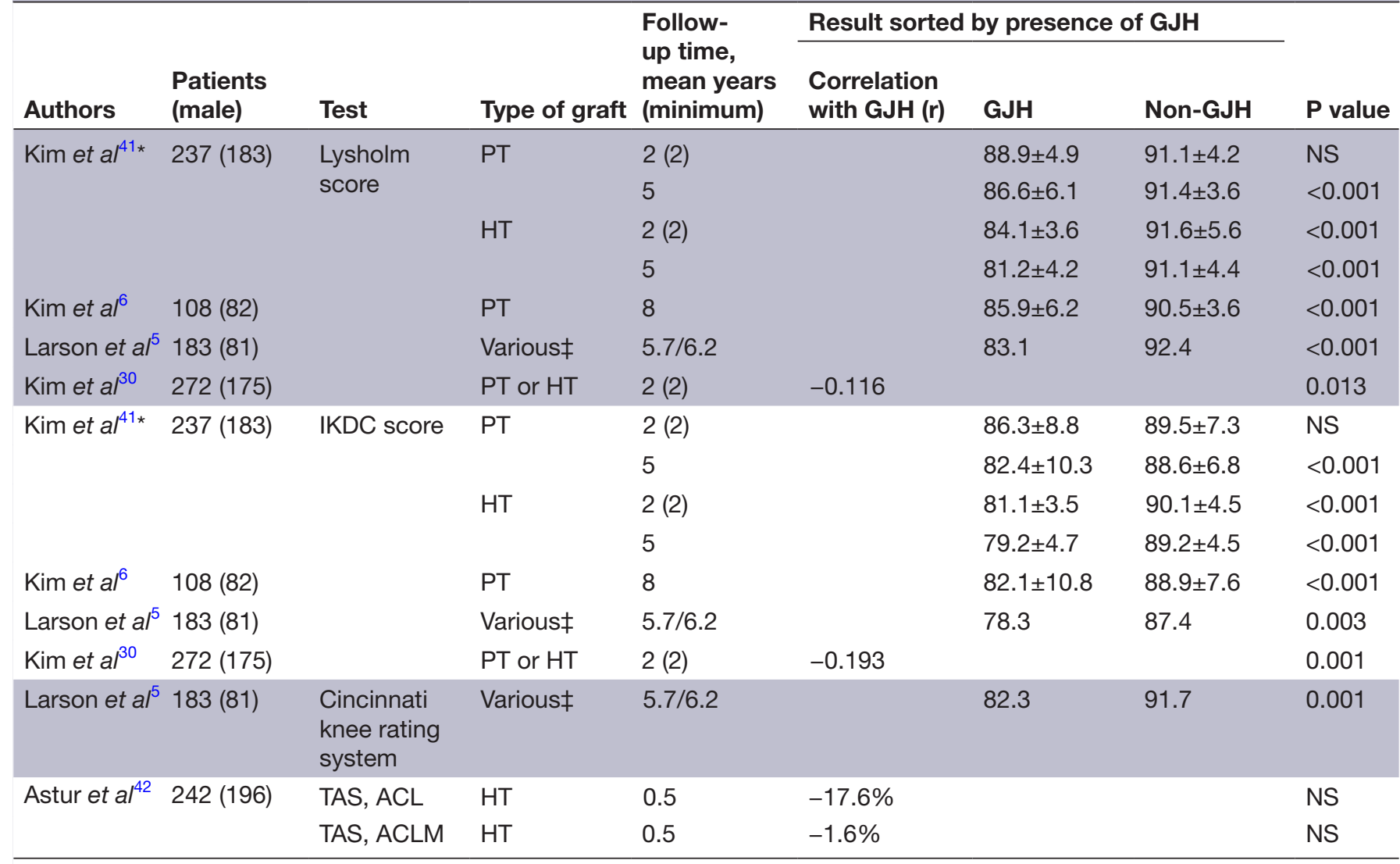

${ }^{*}$ The $p$ values of the Bonferroni correction analysis are presented for this publication.

†The exact follow-up time was not disclosed.

†PT autograft (46), PT allograft (43), quadrupled HT autograft (85), tibialis anterior allograft (9).

ACLM, combination of ACL and meniscus injury; GJH, generalised joint hypermobility; HT, hamstring tendon ; IKDC, International Knee

Documentation Committee; NS, not significant; PT, patellar tendon; TAS, Tegner Activity Scale.

ACL reconstruction. Using patient-reported outcome measurements is important in order to quantify patient satisfaction. The subgroup of patients with GJH are already at a disadvantage preinjury, as is illustrated by a recent study of 1006 non-injured Danish adults demonstrating that patients with GJH or knee joint hypermobility had a twofold probability of reporting symptoms such as knee pain, inferior performance of usual activity and reduced health-related quality of life. ${ }^{15}$ It is therefore especially important to optimise both surgical interventions and rehabilitation in this group of patients.

In this systematic review, OA was evaluated in two studies with ACL-injured patients showing no difference in $\mathrm{OA}$ at short-term to mid-term follow-ups with respect to the presence of GJH. Previous studies have assessed the association between $\mathrm{OA}$ and $\mathrm{GJH}$ in the general population with inconclusive results. ${ }^{54-56}$ It has been suggested that cross-sectional investigations of both $\mathrm{OA}$ and GJH at older ages may be difficult to interpret, as hypermobility might be a marker of fitness, associated with less OA. ${ }^{55}$ More studies, with longer follow-ups beyond 10 years, are needed to draw definite conclusions. In line with the argument above, it is recommended to assess $\mathrm{GJH}$ in these patients preoperatively, with a subsequent long-term follow-up to avoid misinterpretation of the results.

\section{Should the presence of GJH influence graft choice?}

The choice of graft might be particularly important in patients with GJH. This review reported that patients receiving HT autografts had increased instrumented anteroposterior laxity and inferior Lysholm and IKDC scores compared with patients receiving PT autografts. In the general population, previous systematic reviews have reported that PT autografts produce less anteroposterior laxity but with poorer results regarding postoperative complications, including anterior knee pain and kneeling pain, compared with HT autografts. ${ }^{57-59}$ In terms of laxity, the same results were found in this review for the subset of patients with GJH. However, in contrast to the general ACL-reconstructed population, ${ }^{60}$ patients with GJH receiving the PT autograft also benefited from superior subjective outcomes, according to the results of the present review. With the knowledge available at present, a PT autograft appears to be the better alternative compared with HT autografts in patients with GJH. 


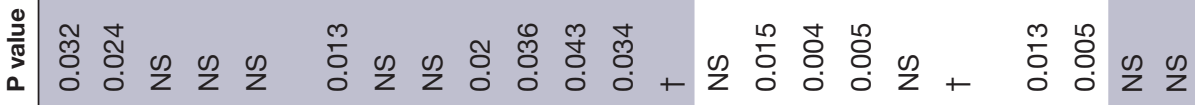

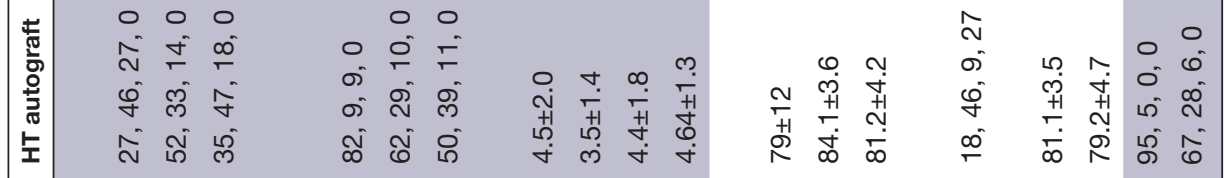

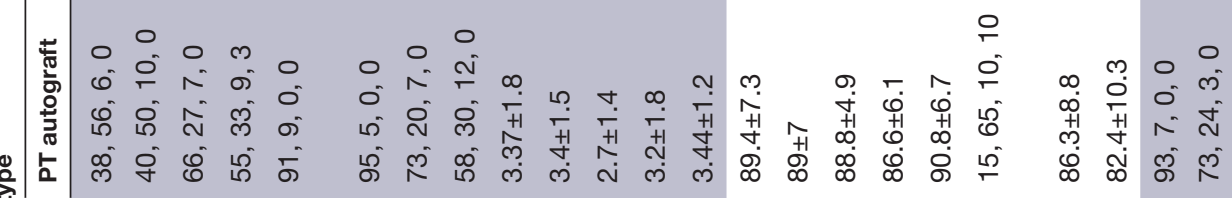

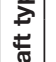
๘

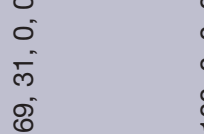

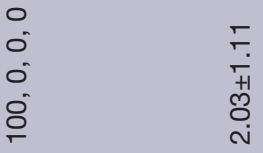

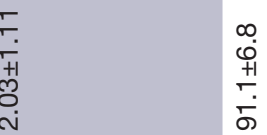

$\bar{i}$
$\stackrel{+}{+}$
$\dot{\gamma}$

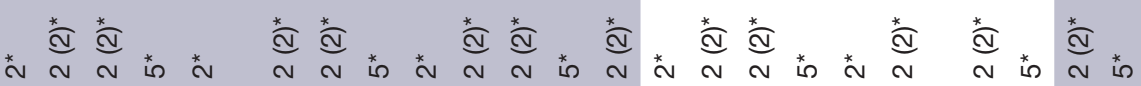

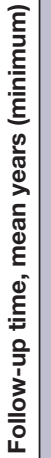

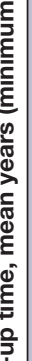
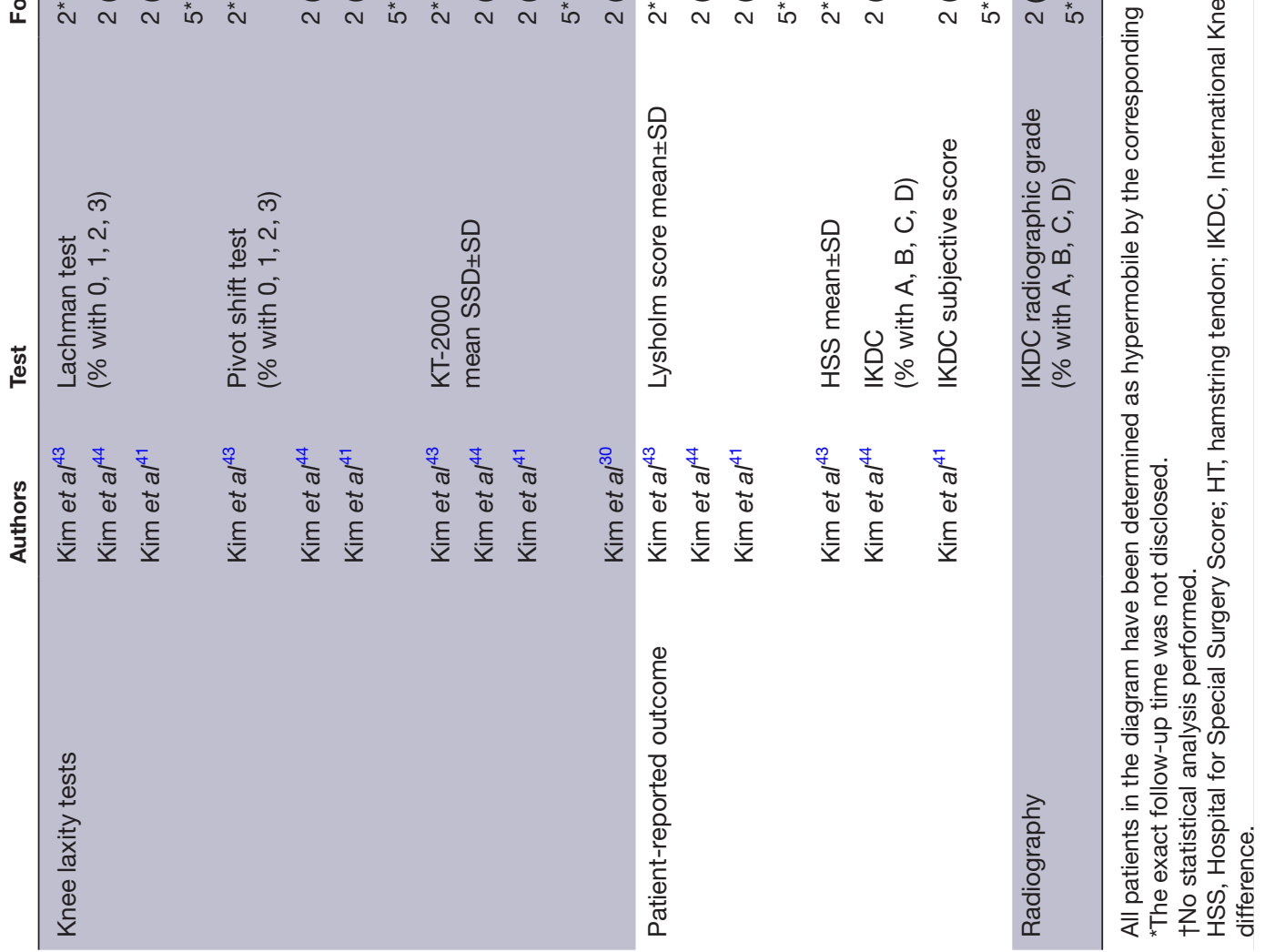

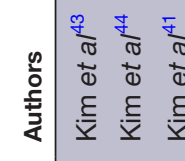

$\frac{7}{\frac{2}{2}} \frac{\pi}{2} \frac{\pi}{2}$

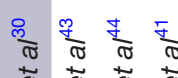

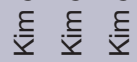

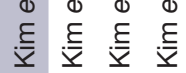
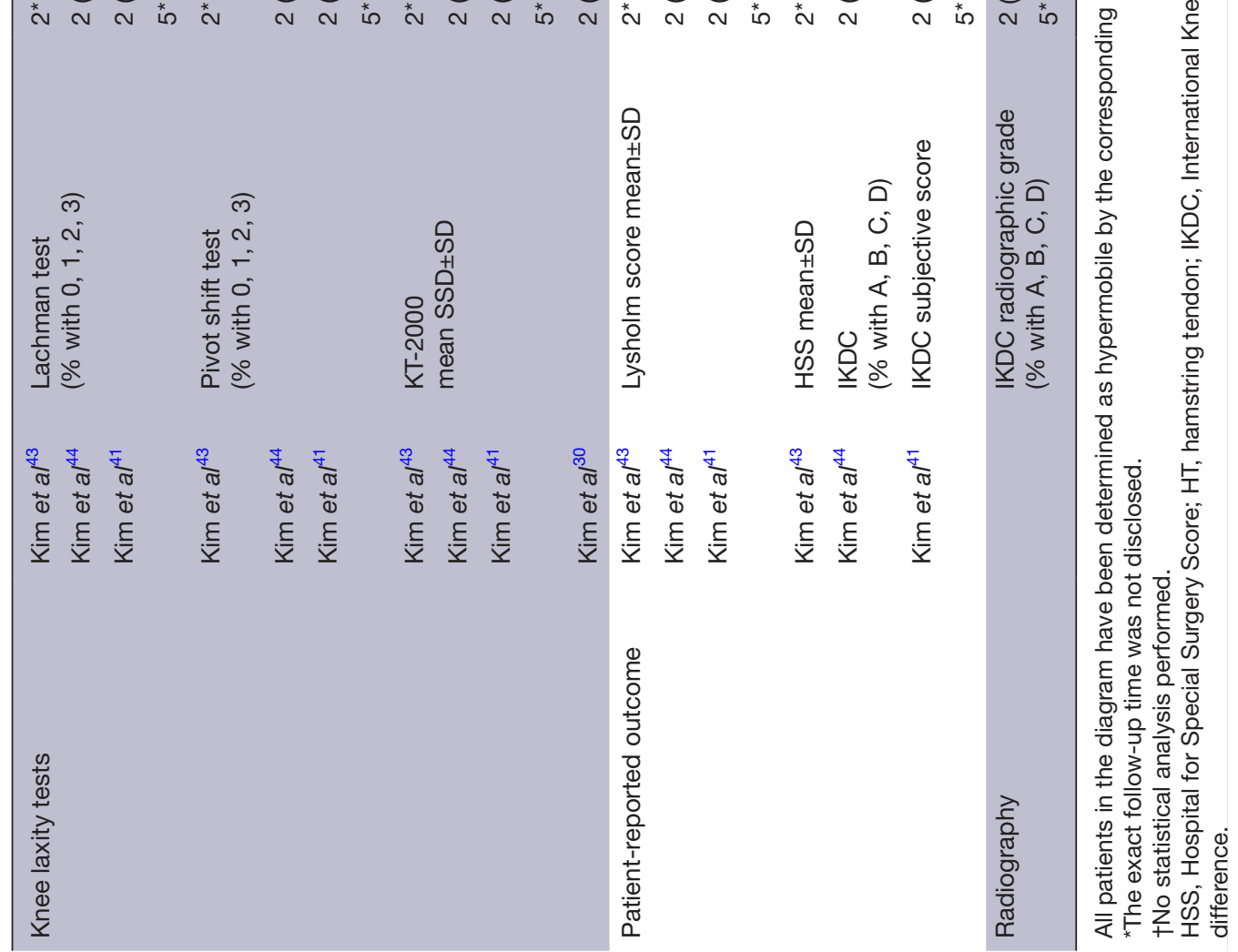


\section{Limitations and strengths}

A few limitations relate to the overall quality of the studies included in this review. First, several methods were used to assess GJH using different cut-offs for the definition of hypermobility. Consequently, no general recommendations could be given in terms of aspects of treatment related to a specific degree of hypermobility; only general statements can be made.

Second, the lack of an a priori sample-size calculation of the involved studies raises concerns about a type-II error possibly being present in several of the studies in this review.

Third, the heterogeneity of the assessment methods for definition of GJH and the multiple confounding variables limits the ability to pool data for a quantitative analysis. This review focused in particular on the confounders sex and age, as female sex and younger age are risk factors for primary ACL injury and ACL revision ${ }^{16} 61$ and GJH is more common at younger ages and in females. ${ }^{11}$ However, there are many other important potential confounders, such as extrinsic and intrinsic risk factors and injury mechanisms, that were not acknowledged in the majority of the studies. One of the studies in this review conducted both multivariable adjusted and unadjusted analyses. When the authors adjusted for known confounders, this changed the regression coefficients by at least $10 \%$, emphasising the importance of considering potential confounders in analyses of risk factors for ACL injury. ${ }^{62}$

Last, one first author (Dr Sung-Jae Kim) contributed with five of the studies $(22 \%)$ eligible for this review. His research group provided the majority of or all the available evidence on the following aspects of this review: radiography, postoperative knee laxity, postoperative clinical outcome and the effect of graft type in patients with GJH. This limits the generalisability of our conclusions since joint hypermobility varies among ethnic groups ${ }^{11}$ and there is an ongoing debate concerning the possible association between ACL injury and genetic variations/ polymorphisms. $^{63}$

Considering a lack of studies and the limitations listed above, there was insufficient evidence to draw any definitive conclusions at present for the following analyses; bilateral ACL injuries, graft failure and return to physical activity.

Particular strong points include the homogeneous primary end-point, ACL injury, in contrast to more vaguely defined knee injury assessed in a previous systematic review. ${ }^{3}$ Moreover, this review includes primary ACL injury risk, graft-failure risk and postoperative outcome, giving a comprehensive overview of the scientific evidence relating to the association between the ACLinjured athlete and GJH.

\section{Future perspectives}

With respect to future studies, there are some aspects that could improve the quality and between-study comparisons in the future. Several methods with different cut-offs were used to establish the diagnosis of GJH. It is important to standardise the definition of GJH across all subspecialised fields in order to create comparable data.
The recommendation is to use the definition of $\mathrm{GJH}$ presented in the consensus document by Malfait et al in 2017, presenting cut-offs as follows: $\geq 6$ for pre-pubertal children and adolescents, $\geq 5$ for pubertal males and females up to the age of 50 , and $\geq 4$ for those $>50$ years of age. ${ }^{8}$ In the ACL-injured individual, the use of the 5-point questionnaire $^{810}$ or an injury allowance point $t^{64}$ is recommended to mitigate the bias of the disturbed range of motion of the ACL-injured knee. Moreover, the use of grafts should be meticulously considered in patients with GJH. Future randomised controlled studies are needed to draw definite conclusions regarding the preferred use of grafts and the use of surgical techniques in these patients. On current evidence, we recommend the use of PT autografts.

\section{CONCLUSIONS}

In males, GJH was associated with an increased risk of unilateral ACL injury. Moreover, GJH was associated with increased postoperative knee laxity and inferior patientreported outcome. Based on the available evidence, a PT autograft appears to be superior to a HT autograft in patients with GJH. However, the included studies were heterogeneous and there is a need for consensus in the assessment of $\mathrm{GJH}$ in sports medicine.

\section{Author affiliations}

${ }^{1}$ Department of Orthopedics, Institute of Clinical Sciences, Sahlgrenska Academy, University of Gothenburg, Gothenburg, Sweden

${ }^{2}$ Department of Health and Rehabiltation, Institute of Neuroscience and Physiology, Sahlgrenska Academy, University of Gothenburg, Gothenburg, Sweden

${ }^{3}$ Department of Sports Science and Clinical Biomechanics, Syddansk Universitet Det Sundhedsvidenskabelige Fakultet, Odense, Denmark

${ }^{4}$ Department of Orthopedics, Sahlgrenska University Hospital, Gothenburg, Sweden ${ }^{5}$ Department of Surgery, Division of Orthopaedic Surgery, McMaster University, Hamilton, Ontario, Canada

\section{Twitter David Sundemo @DSundemo and Eric Hamrin Senorski @senorsk}

Acknowledgements The authors would like to acknowledge the assistance of the expert medical librarian, Helen Sjöblom, for the siginficant help she provided.

Contributors DS made contributions to the design of the study, interpretation of data and for drafting the work. KS, EHS and JK made contributions to the design of the work, interpretation of data and for critical revision for intellectual content. LK, $\mathrm{AH}, \mathrm{ORA}$ and BJ-K made contributions for the interpretation of data and for critical revision for intellectual content. All authors gave final approval for the final version and agree to be accountable for all aspects of the work.

Funding The authors have not declared a specific grant for this research from any funding agency in the public, commercial or not-for-profit sectors.

Competing interests ORA has declared speakers bureau for Conmed.

Patient consent for publication Not required.

Provenance and peer review Not commissioned; externally peer reviewed.

Data availability statement All data relevant to the study are included in the article or uploaded as supplementary information.

Open access This is an open access article distributed in accordance with the Creative Commons Attribution Non Commercial (CC BY-NC 4.0) license, which permits others to distribute, remix, adapt, build upon this work non-commercially, and license their derivative works on different terms, provided the original work is properly cited, appropriate credit is given, any changes made indicated, and the use is non-commercial. See: http://creativecommons.org/licenses/by-nc/4.0/.

\section{ORCID iDs}

David Sundemo http://orcid.org/0000-0002-5871-1636 
Eric Hamrin Senorski http://orcid.org/0000-0002-9340-0147

\section{REFERENCES}

1 Bahr R, Krosshaug T. Understanding injury mechanisms: a key component of preventing injuries in sport. $\mathrm{Br} J$ Sports Med 2005;39:324-9.

2 Alentorn-Geli E, Myer GD, Silvers HJ, et al. Prevention of noncontact anterior cruciate ligament injuries in soccer players. Part 1: mechanisms of injury and underlying risk factors. Knee Surg Sports Traumatol Arthrosc 2009;17:705-29.

3 Pacey V, Nicholson LL, Adams RD, et al. Generalized joint hypermobility and risk of lower limb joint injury during sport: a systematic review with meta-analysis. Am J Sports Med 2010;38:1487-97.

4 Uhorchak JM, Scoville CR, Williams GN, et al. Risk factors associated with noncontact injury of the anterior cruciate ligament: a prospective four-year evaluation of 859 West Point cadets. Am J Sports Med 2003;31:831-42.

5 Larson CM, Bedi A, Dietrich ME, et al. Generalized hypermobility, knee hyperextension, and outcomes after anterior cruciate ligament reconstruction: prospective, case-control study with mean 6 years follow-up. Arthroscopy 2017.

6 Kim S-J, Choi CH, Lee S-K, et al. Minimum two-year follow-up of anterior cruciate ligament reconstruction in patients with generalized joint laxity. J Bone Joint Surg Am 2018;100:278-87.

7 Shimozaki K, Nakase J, Takata Y, et al. Greater body mass index and hip abduction muscle strength predict noncontact anterior cruciate ligament injury in female Japanese high school basketball players. Knee Surg Sports Traumatol Arthrosc 2018;26:3004-11.

8 Malfait F, Francomano C, Byers P, et al. The 2017 International classification of the Ehlers-Danlos syndromes. Am. J. Med. Genet. 2017;175:8-26.

9 Castori M, Tinkle B, Levy $\mathrm{H}$, et al. A framework for the classification of joint hypermobility and related conditions. Am J Med Genet C Semin Med Genet 2017;175:148-57.

10 Hakim AJ, Grahame R. A simple questionnaire to detect hypermobility: an adjunct to the assessment of patients with diffuse musculoskeletal pain. Int J Clin Pract 2003;57:163-6.

11 Remvig L, Jensen DV, Ward RC. Epidemiology of general joint hypermobility and basis for the proposed criteria for benign joint hypermobility syndrome: review of the literature. $J$ Rheumatol 2007;34:804-9.

12 Moraes DAde, Baptista CA, Crippa JAS, et al. Translation into Brazilian Portuguese and validation of the five-part questionnaire for identifying hypermobility. Rev Bras Reumatol 2011;51:53-69.

13 Mulvey MR, Macfarlane GJ, Beasley M, et al. Modest association of joint hypermobility with disabling and limiting musculoskeletal pain: results from a large-scale general population-based survey. Arthritis Care Res 2013;65:1325-33.

14 Juul-Kristensen B, Østengaard L, Hansen S, et al. Generalised joint hypermobility and shoulder joint hypermobility, - risk of upper body musculoskeletal symptoms and reduced quality of life in the general population. BMC Musculoskelet Disord 2017;18.

15 Junge T, Henriksen P, Hansen S, et al. Generalised joint hypermobility and knee joint hypermobility: prevalence, knee joint symptoms and health-related quality of life in a Danish adult population. Int J Rheum Dis 2019;22:288-96.

16 Arendt E, Dick R. Knee injury patterns among men and women in collegiate basketball and soccer. NCAA data and review of literature. Am J Sports Med 1995;23:694-701.

17 Roos H, Ornell M, Gärdsell P, et al. Soccer after anterior cruciate ligament injury - an incompatible combination? A national survey of incidence and risk factors and a 7-year follow-up of 310 players. Acta Orthop Scand 1995;66:107-12.

18 Trojian TH, Collins S. The anterior cruciate ligament tear rate varies by race in professional women's basketball. Am J Sports Med 2006;34:895-8.

19 Dallinga JM, Benjaminse A, Lemmink KAPM. Which screening tools can predict injury to the lower extremities in team sports?: a systematic review. Sports Med 2012;42:791-815.

20 Pfeifer CE, Beattie PF, Sacko RS, et al. Risk factors associated with non-contact anterior cruciate ligament injury: a systematic review. Int $J$ Sports Phys Ther 2018;13:575-87.

21 Stewart LA, Clarke M, Rovers M, et al. Preferred reporting items for systematic review and meta-analyses of individual participant data: the PRISMA-IPD statement. JAMA 2015;313:1657-65.

22 Bramer W, Bain P. Updating search strategies for systematic reviews using EndNote. J Med Libr Assoc 2017;105:285-9.

23 Ouzzani M, Hammady H, Fedorowicz Z, et al. Rayyan-a web and mobile APP for systematic reviews. Syst Rev 2016;5:210.
24 Slim K, Nini E, Forestier D, et al. Methodological index for nonrandomized studies (MINORS): development and validation of a new instrument. ANZ J Surg 2003;73:712-6.

25 Khan W, Khan M, Alradwan $\mathrm{H}$, et al. Utility of intra-articular hip injections for femoroacetabular impingement: a systematic review. Orthop J Sports Med 2015;3.

26 Nilstad A, Andersen TE, Bahr R, et al. Risk factors for lower extremity injuries in elite female soccer players. Am J Sports Med 2014;42:940-8.

27 Söderman K, Alfredson H, Pietilä T, et al. Risk factors for leg injuries in female soccer players: a prospective investigation during one out-door season. Knee Surg Sports Traumatol Art 2001;9:313-21.

28 Sueyoshi T, Emoto G, Yuasa T. Generalized joint laxity and ligament injuries in high school-aged female volleyball players in Japan. Orthop J Sports Med 2016;4.

29 Harner CD, Paulos LE, Greenwald AE, et al. Detailed analysis of patients with bilateral anterior cruciate ligament injuries. Am J Sports Med 1994;22:37-43.

30 Kim S-J, Moon H-K, Kim S-G, et al. Does severity or specific joint laxity influence clinical outcomes of anterior cruciate ligament reconstruction? Clin Orthop Relat Res 2010;468:1136-41.

31 Kramer LC, Denegar CR, Buckley WE, et al. Factors associated with anterior cruciate ligament injury: history in female athletes. J Sports Med Phys Fitness 2007;47:446-54.

32 Vacek PM, Slauterbeck JR, Tourville TW, et al. Multivariate analysis of the risk factors for first-time noncontact ACL injury in high school and college athletes: a prospective cohort study with a nested, matched case-control analysis. Am J Sports Med 2016;44:1492-501.

33 Akhtar MA, Bhattacharya R, Keating JF. Generalised ligamentous laxity and revision ACL surgery: is there a relation? Knee 2016;23:1148-53.

34 Anderson AF, Lipscomb AB, Liudahl KJ, et al. Analysis of the intercondylar notch by computed tomography. Am J Sports Med 1987;15:547-52.

35 Ramesh R, Von Arx O, Azzopardi T, et al. The risk of anterior cruciate ligament rupture with generalised joint laxity. J Bone Joint Surg $\mathrm{Br}$ 2005;87-B:800-3.

36 Vaishya R, Hasija R. Joint hypermobility and anterior cruciate ligament injury. J Orthop Surg 2013;21:182-4.

37 Stijak L, Kadija M, Djulejić V, et al. The influence of sex hormones on anterior cruciate ligament ruptures in males. Knee Surg Sports Traumatol Arthrosc 2015;23:3578-84.

38 Scerpella TA, Stayer TJ, Makhuli BZ. Ligamentous laxity and non-contact anterior cruciate ligament tears: a gender-based comparison. Orthopedics 2005;28:656-60.

39 Stijak L, Kadija M, Djulejić V, et al. The influence of sex hormones on anterior cruciate ligament rupture: female study. Knee Surg Sports Traumatol Arthrosc 2015;23:2742-9.

40 Motohashi M. Profile of bilateral anterior cruciate ligament injuries: a retrospective follow-up study. J Orthop Surg 2004;12:210-5.

$41 \mathrm{Kim}$ S-J, Choi CH, Kim S-H, et al. Bone-patellar tendon-bone autograft could be recommended as a superior graft to hamstring autograft for ACL reconstruction in patients with generalized joint laxity: 2- and 5-year follow-up study. Knee Surg Sports Traumatol Arthrosc 2018;26:2568-79.

42 Astur DC, Lara PHS, Santos MA, et al. Influence of joint hypermobility on postoperative results of knee surgery. Acta Ortop Bras 2018;26:19-21.

$43 \mathrm{Kim}$ S-J, Chang J-H, Kim T-W, et al. Anterior cruciate ligament reconstruction with use of a single or double-bundle technique in patients with generalized ligamentous laxity. J Bone Joint Surg Am 2009;91:257-62.

44 Kim S-J, Kim T-E, Lee D-H, et al. Anterior cruciate ligament reconstruction in patients who have excessive joint laxity. $J$ Bone Joint Surg Am 2008;90:735-41.

45 Junge T, Runge L, Juul-Kristensen B, et al. Risk factors for knee injuries in children 8 to 15 years: the CHAMPS study dk. Med Sci Sports Exerc 2016;48:655-62.

46 Bjordal JM, Arnły F, Hannestad B, et al. Epidemiology of anterior cruciate ligament injuries in soccer. Am J Sports Med 1997;25:341-5.

47 Hewett TE, Myer GD, Ford KR, et al. Biomechanical measures of neuromuscular control and valgus loading of the knee predict anterior cruciate ligament injury risk in female athletes: a prospective study. Am J Sports Med 2005;33:492-501.

48 Junge T, Wedderkopp N, Thorlund JB, et al. Altered knee joint neuromuscular control during landing from a jump in 10-15 year old children with generalised joint hypermobility. A substudy of the CHAMPS-study Denmark. J Electromyogr Kinesiol 2015;25:501-7. 
49 Jensen BR, Olesen AT, Pedersen MT, et al. Effect of generalized joint hypermobility on knee function and muscle activation in children and adults. Muscle Nerve 2013;48:762-9.

50 Schmidt H, Pedersen TL, Junge T, et al. Hypermobility in adolescent athletes: pain, functional ability, quality of life, and musculoskeletal injuries. J Orthop Sports Phys Ther 2017;47:792-800.

51 Li H, Zeng C, Wang Y, et al. Association between magnetic resonance dimensions and anterior cruciate ligament injury: a metaanalysis. Arthroscopy 2018;34:889-900.

52 Herzberg SD, Motu'apuaka ML, Lambert W, et al. The effect of menstrual cycle and contraceptives on ACL injuries and laxity: a systematic review and meta-analysis. Orthop J Sports Med 2017;5.

53 Grahame R. Joint hypermobility and genetic collagen disorders: are they related? Arch Dis Child 1999;80:188-91.

54 Scott D, Bird H, Wright V. Joint laxity leading to osteoarthrosis. Rheumatology 1979;18:167-9.

55 Dolan AL, Hart DJ, Doyle DV, et al. The relationship of joint hypermobility, bone mineral density, and osteoarthritis in the genera population: the Chingford study. J Rheumatol 2003;30:799-803.

56 Flowers PPE, Cleveland RJ, Schwartz TA, et al. Association between general joint hypermobility and knee, hip, and lumbar spine osteoarthritis by race: a cross-sectional study. Arthritis Res Ther 2018;20.

57 Schuette HB, Kraeutler MJ, Houck DA, et al. Bone- versus hamstring tendon autografts for primary anterior cruciate ligament reconstruction: a systematic review of overlapping meta-analyses. Orthop J Sports Med 2017;5.

58 Cristiani R, Sarakatsianos V, Engström B, et al. Increased knee laxity with hamstring tendon autograft compared to patellar tendon autograft: a cohort study of 5462 patients with primary anterior cruciate ligament reconstruction. Knee Surg Sports Traumatol Arthrosc 2019;27:381-8.

59 Cristiani R, Forssblad M, Engström B, et al. Risk factors for abnormal anteroposterior knee laxity after primary anterior cruciate ligament reconstruction. Arthroscopy 2018;34:2478-84.

60 Xie X, Liu X, Chen Z, et al. A meta-analysis of bone-patellar tendonbone autograft versus four-strand hamstring tendon autograft for anterior cruciate ligament reconstruction. Knee 2015;22:100-10.

61 Andernord D, Desai N, Björnsson H, et al. Patient predictors of early revision surgery after anterior cruciate ligament reconstruction: a cohort study of 16,930 patients with 2-year follow-up. Am J Sports Med 2015;43:121-7.

62 Myer GD, Ford KR, Paterno MV, et al. The effects of generalized joint laxity on risk of anterior cruciate ligament injury in young female athletes. Am J Sports Med 2008;36:1073-80.

63 Kaynak M, Nijman F, van Meurs J, et al. Genetic variants and anterior cruciate ligament rupture: a systematic review. Sports Med 2017;47:1637-50.

64 Stewart DR, Burden SB. Does generalised ligamentous laxity increase seasonal incidence of injuries in male first division club rugby players? Br J Sports Med 2004;38:457-60. 